\title{
Assessment of the Accessibility of Users in Primary Health Care
}

\author{
Tainara Lôrena dos Santos Ferreira ${ }^{1}$, Iris do Céu Clara Costa ${ }^{2}$, Fábia Barbosa de Andrade ${ }^{1}$ \\ ${ }^{1}$ Nursing, Faculty of Health Sciences of Trairi (FACISA), Federal University of Rio Grande do Norte (UFRN), Santa Cruz, Brazil \\ ${ }^{2}$ Odontology Department, Federal University of Rio Grande do Norte, Natal, Brazil \\ Email: tainara_lorena@hotmail.com, irisdoceu.ufrn@gmail.com, fabiabarbosabr@yahoo.com.br
}

How to cite this paper: Ferreira, T.L.S., Costa, I.C.C. and de Andrade, F.B. (2016) Assessment of the Accessibility of Users in Primary Health Care. Open Journal of Epidemiology, 6, 183-190.

http://dx.doi.org/10.4236/ojepi.2016.64020

Received: March 22, 2016

Accepted: November 5, 2016

Published: November 8, 2016

Copyright $\odot 2016$ by authors and Scientific Research Publishing Inc. This work is licensed under the Creative Commons Attribution International License (CC BY 4.0).

http://creativecommons.org/licenses/by/4.0/ (c) (i) Open Access

\begin{abstract}
Objectives: The goal of this project was to evaluate the quality of the accessibility of the adult population to services in Primary Health Care, with a view to contribute to the development of measures that will propose improvement in the offered assistance. Methods: This is a quantitative and evaluative study made in the municipality of Santa Cruz, State of Rio Grande do Norte, Brazil, with a sample of 180 people. The study was approved by the Ethics and Research Committee of the Federal University of Rio Grande do Norte under Opinion number 152/2012. Results: It was found that the adult population classified the quality of care from regular to good, showing an association with the waiting time, time spent from the unit to one's house and the reception. Conclusions: It could be concluded that this study contributes to the development of strategies able to provide a full and equitable care to the adult population in the primary health care network, since this is the gateway to other levels of care, because it aims to promote adult health and prevent diseases.
\end{abstract}

\section{Keywords}

Health Services Accessibility, Primary Health Care, Health Evaluation

\section{Introduction}

Although health is the right and duty of the state, according to the Constitution of 1988 , it is necessary to ensure universal and equal access to actions and services, in order to comply with the promotion, protection and recovery of health, as well as guarantee full time attendance through the Unified Health System (UHS). Thus, the UHS bases the services of Primary Health Care (PHC) and as a community model deployed in Brazil, seeks for the realization of a better assistance and establishment of linkages between users and health professionals. 
Acting according to the UHS' principles, means that every health institution should have the commitment to meet with technical and scientific quality and solving the health needs of the user in a resolute manner, ensuring the access and reception needed, especially in PHC [1].

In the context of Primary Health Care, some attributes are proposed so that health care is offered with quality. The pillars that structure the PHC are structural elements, i.e., attributes of the health service system consisting of: first contact access, comprehensiveness, longitudinality, coordination, family and community orientation and cultural competence [2].

Considering the importance of accessibility, it is known that access is still fragile due to some existing inequalities, but health services cannot be responsible for this inequality [3]. According to the perceived national reality, the primary services have grown so that more people may have full time care, according to the cycle of life. This reflex expansion indicates for these attributes to be implemented in the community.

To get efficient and effective health assistance, it is important for the population to have access of quality to the health services [4]. When the right to access and hosting by the UHS is guaranteed, the health services promote better achievement of health and continuity of care in any health level, because they are a part of the essential elements to assistance [1].

Regarding accessibility, there are still other factors that may cause malfunctions, e.g., interrupted flows, routines and strategies to counter or evade the demand, inadequate or incomplete records of information about the user and his family, the lack or inadequacy of physical, financial and human resources as well as of planning and management services: excessive waiting for appointments and procedures, test results, definition of treatment to be followed, few educational activities with and in the community [5].

To speak about access is to speak about reception. In Brazil, there is a health policy entitled National Humanization Policy, it talks about the reception and brings a technical and operational slope on ways to accommodate the user in healthcare facilities. Concerning the reception, this tends to decentralize the concept that users have about their health, making them understand that health is not only the result of a process, and that this follows a broad concept, besides being influenced by physical, emotional, religious, economic, social, cultural, environmental and psychological factors, developing this user's desired autonomy.

Thus, the present work is justified by the fact that access is an important tool for maintaining and ensuring the population's health. When speaking of principles proposed by the UHS, ensuring access to health comes first, because the user who is ill needs to be upheld, and one that is healthy must have guaranteed health actions, understood as prevention of diseases and health promotion. Thus perceiving the importance of ensuring access to services as a promotional factor, protection and recovery of health that aims at a greater resolution of attention, and to ensure the population registered in the PHC to a healthy and active long life. This study aims to evaluate the quality of the adult population's accessibility to services in Primary Health Care. 


\section{Methodology}

This is a quantitative and evaluative study made in the municipality of Santa Cruz, State of Rio Grande do Norte, Brazil. The study was conducted at the Family Health Units chosen by assortment, with the users of the Unified Health System (UHS) that are registered and attended these services. The sample consisted of 180 people that were randomly chosen, not probabilistic and convenience, according to the criteria of inclusion and exclusion.

This study is part of a research entitled Primary Attention to Health: An evaluation study from the users' perspective. The inclusion criterion was for the participants to be older than the age of eighteen, to be registered and reside in the community, and attended the Family Health Unit, to have preserved cognitive skills and to sign the Statement of Informed Consent.

The interviews were performed by students of the course interviewers degree in nursing of UFRN/FACISA, enrolled previously trained, using the instrument Primary Care Assessment Tool (PCATool). The list of suitable for the sample was obtained at the Municipal Santa Cruz/RN Health and, soon after, in the Family Health Unit (USF) where participants are registered, and the interview held at USF in a reserved place and scheduled, in accordance with the inclusion and exclusion criteria, after explanation of the research by the researchers goals, as well as reading and signing the Statement of Informed Consent.

The data were put on a table and analyzed using the Statistical Package for the Social Sciences SPSS, version 22.0. For data analysis were calculated the following statistical averages: The mean, median and standard deviation. Within the bivariate analysis, were performed chi-square tests, using as a convention of significance a probability lower than 0.05 and a confidence interval of $95 \%$. It is worth noting the classification of the service, it was Likert scale, high quality, growing, these being: Poor, bad, regular, good, excellent.

The study followed all the recommendations regarding research with human subjects contained in the Resolution 466/2012 of the National Health Council. The project was approved by the Ethics and Research Committee (ERC) of the Federal University of Rio Grande do Norte (UFRN) under Opinion number 152/2012.

\section{Results}

This study sought to evaluate the quality of access that users are having in the Primary Health Care. For that were interviewed 180 people, of which $76.7 \%(\mathrm{n}=138)$ were women and $23.3 \%(\mathrm{n}=42)$ men, the minimum age was of 20 years and maximum of 59 years with a mean of 36.65 , median of 34.00 and standard deviation of 11.554 . The average education level of respondents, was 6.92 years of study, median of 6.00 years, standard deviation of 3.89 (Table 1).

The data revealed a Cronbach's alpha of 0.81 which reveals the existence of internal validity and reliable data in the construct. The ANOVA Cochran test was also calculated, being significant at $\mathrm{p}=0.00$, which also showed the homogeneity of the va- 
riances. This shows that the grading scale is feasible and trustworthy to be used in the PHC network and, through it, evaluate the quality of care provided to the adult population.

In Table 2, as to the classification of service from the user's perspective, it can be seen that $46.1 \%(n=83)$ users classify the service as regular, followed by $25.6 \%(n=46)$ that classify it as good.

With respect to the users' responses regarding the time spent from their houses to the health service, it was observed that in Table 3, 93.9\% $(n=169)$ users affirmed they take between 0 to 15 minutes, while $4.4 \%(n=08)$ users ensured they took between 16 to 30 minutes. The chi-square test revealed a significant association between service quality and time spent to get to the clinic with the value of $\mathrm{p}<0.05$, revealing that users take between 0 - 15 minutes classify mostly the service as regular, followed for good.

Table 4 refers to the receiving by the professionals before the consultation (reception),

Table 1. Socio-demographic information of the respondents. Santa Cruz/RN, Brazil, 2016.

\begin{tabular}{cccc}
\hline Variables & Mean & Median & Std. deviation \\
\hline Education-years studied & 6.92 & 6.00 & 3.89 \\
Age & 36.65 & 34.00 & 11.554 \\
\hline
\end{tabular}

Table 2. Classification of service in Primary Health Care from the user's perspective. Santa Cruz/RN, Brazil, 2016.

\begin{tabular}{ccccccc}
\hline & Poor & Bad & Regular & Good & Excellent & Total \\
\hline $\begin{array}{c}\text { Classification } \\
\text { of service } \\
\text { quality }\end{array}$ & $\begin{array}{c}16.7 \% \\
(\mathrm{n}=30)\end{array}$ & $\begin{array}{c}8.9 \% \\
(\mathrm{n}=16)\end{array}$ & $\begin{array}{c}46.1 \% \\
(\mathrm{n}=83)\end{array}$ & $\begin{array}{c}25.6 \% \\
(\mathrm{n}=46)\end{array}$ & $\begin{array}{c}2.8 \% \\
(\mathrm{n}=05)\end{array}$ & $\begin{array}{c}100.0 \% \\
(\mathrm{n}=180)\end{array}$ \\
\hline
\end{tabular}

Table 3. Correlation between the classification of service in Primary Health Care and the time spent by the users from their houses to the health service. Santa Cruz/RN, Brazil, 2016.

\begin{tabular}{cccccc}
\hline & $\begin{array}{c}\text { From } 0 \text { to } \\
15 \text { min. }\end{array}$ & $\begin{array}{c}\text { From 16 to } \\
30 \text { min. }\end{array}$ & $\begin{array}{c}\text { From 31 to } \\
45 \mathrm{~min} .\end{array}$ & $\begin{array}{c}\text { More than } \\
60 \mathrm{~min} .\end{array}$ & $\mathrm{p}<0.05$ \\
\hline $\begin{array}{c}\text { Time spent by the user between } \\
\text { his/her home and the health care } \\
\text { unit }\end{array}$ & $\begin{array}{c}93.9 \% \\
(\mathrm{n}=169)\end{array}$ & $\begin{array}{c}4.4 \% \\
(\mathrm{n}=08)\end{array}$ & $\begin{array}{c}0.6 \% \\
(\mathrm{n}=01)\end{array}$ & $\begin{array}{c}1.1 \% \\
(\mathrm{n}=02)\end{array}$ & 0.023 \\
\hline
\end{tabular}

Table 4. Correlation between classifications of service in Primary Health Care, the receiving by the professionals before the user enters for a consultation, and guidance about the acquisition of free medicines. Santa Cruz/RN, Brazil, 2016.

\begin{tabular}{ccccccc}
\hline & Never & Rarely & Sometimes & Frequently & Always & $\mathrm{p}<0.05$ \\
\hline $\begin{array}{c}\text { Receiving by professionals } \\
\text { before de appointment } \\
\text { (reception) }\end{array}$ & $\begin{array}{c}12.2 \% \\
(\mathrm{n}=22)\end{array}$ & $\begin{array}{c}6.1 \% \\
(\mathrm{n}=11)\end{array}$ & $\begin{array}{c}18.3 \% \\
(\mathrm{n}=33)\end{array}$ & $\begin{array}{c}3.9 \% \\
(\mathrm{n}=07)\end{array}$ & $\begin{array}{c}59.4 \% \\
(\mathrm{n}=107)\end{array}$ & 0.042 \\
$\begin{array}{c}\text { Orientations as to the } \\
\text { acquisition of free } \\
\text { medicine }\end{array}$ & $\begin{array}{c}33.9 \% \\
(\mathrm{n}=61)\end{array}$ & $\begin{array}{c}9.4 \% \\
(\mathrm{n}=17)\end{array}$ & $\begin{array}{c}20.0 \% \\
(\mathrm{n}=36)\end{array}$ & $\begin{array}{c}2.8 \% \\
(\mathrm{n}=05)\end{array}$ & $\begin{array}{c}33.9 \% \\
(\mathrm{n}=61)\end{array}$ & 0.005 \\
\hline
\end{tabular}


and it reports that $59.4 \%(\mathrm{n}=107)$ users verbalized it has always been done, followed by $18.3 \%(n=33)$ in a few times. The table also references regarding professionals guiding the user on the acquisition of free medicines, and in this aspect, 33.9\% ( $\mathrm{n}=61)$ said they have never received such information, 33.9\% $(\mathrm{n}=61)$ have always received it and $20.0 \%(n=36)$ sometimes. When the correlation existing between the variables of service quality and the receiving before the appointment is analyzed, as well as the orientation to the purchase of free medicine, is found a value of $\mathrm{p}<0.05$.

Regarding the amount of time waiting to start the appointment, Table 5, 40.6\% ( $\mathrm{n}=$ 73) users stated they wait from 16 to 30 minutes and $23.9 \%(n=43)$ verbalized they wait from 46 to 60 minutes. One may notice a correlation between the quality of service and the amount of time waiting to start the appointment by finding a value of $\mathrm{p}<0.05$ in the chi-square test.

With respect to the professional propose home visits when the user is unable to attend the service, $92.8 \%(\mathrm{n}=167)$ users affirmed that the professional has never proposed this option, while $2.8 \%$ guaranteed often receiving the proposal. The chi-square for this data had a value of $\mathrm{p}=0.843$, so it is not meaningful, because it revealed a value of $\mathrm{p}>0.05$.

\section{Discussions}

The results show a correlation between the user's accessibility to the service and the classification of quality of service. As shown in Table 2, according to the classification of care in PHC, it is known that for the effectiveness of programs and services the user classification is presented as fundamental as it offers subsidies for reformulations aimed at improving care and guiding towards strategies for the commitment with quality of services and offered actions, guided by the PHC's attributes.

The fundamental sense when theorizing in the evaluation of health services is primarily to seek to convert concepts into strategies, criteria and standards of measurement, in order to contribute to useful measures and support improvement under the scope of services [6].

In Table 3, it was observed that the proximity of health services to their houses contributes for the user to consider the service to be of quality, since it favors access to the service. So more than present themselves as a gateway to other levels of care, PHC, by its user-centered nature in an integral form and its relationship with the community, is characterized by the quality of service provided through the continuum of care.

What may affect the population's access is the demographic access, which is characterized by the transportation type, travel time and distance from the individual's home

Table 5. Correlation between classification of service in Primary Health Care and the amount of time waiting to start the appointment. Santa Cruz/RN, Brazil, 2016.

\begin{tabular}{ccccccc}
\hline & $\begin{array}{c}\text { From } 0 \text { to } \\
15 \mathrm{~min} .\end{array}$ & $\begin{array}{c}\text { From } 16 \\
\text { to } 30 \mathrm{~min} .\end{array}$ & $\begin{array}{c}\text { From } 31 \\
\text { to } 45 \mathrm{~min}\end{array}$ & $\begin{array}{c}\text { From } 46 \\
\text { to } 60 \mathrm{~min}\end{array}$ & $\begin{array}{c}\text { More than } \\
60 \mathrm{~min} .\end{array}$ & $\mathrm{p}<0.05$ \\
\hline $\begin{array}{c}\text { Amount of time } \\
\begin{array}{c}\text { waiting to start the } \\
\text { appointment }\end{array}\end{array}$ & $\begin{array}{c}10.0 \% \\
(\mathrm{n}=18)\end{array}$ & $\begin{array}{c}40.6 \% \\
(\mathrm{n}=73)\end{array}$ & $\begin{array}{c}3.9 \% \\
(\mathrm{n}=07)\end{array}$ & $\begin{array}{c}23.9 \% \\
(\mathrm{n}=43)\end{array}$ & $\begin{array}{c}21.7 \% \\
(\mathrm{n}=39)\end{array}$ & 0.020 \\
\hline
\end{tabular}


to the healthcare unit. The approximation of the user's residence with the PHC services reveals a potentiality, since the health-disease process is more heavily looked after by the team of professionals in these services [7].

Table 4, in reference to the reception held prior to the consultation, shows that the users are always received, however, a considerable portion verbalized only sometimes, and others that they were never received, which demonstrates the need to strengthen this practice in the $\mathrm{PHC}$ to contribute to the continuation of care and services, once one articulates with the accessibility to the service for a full and effective assistance.

Access and reception articulate and complement each other in the implementation of practices in health care, from the perspective of integrality of care. With the expansion and structuring of services during the construction process of the Brazilian Unified Health System, in which municipalities have assumed responsibility for the health care of its citizens, especially the Primary Care Network, the debate on access to such services has gained qualitative nuances [8].

In Table 4, with respect to professionals orienting users about obtaining free medicines, through the answers were observed "never" and "sometimes", these orientations need to be made so that they contribute to the achievement of improvements in obtaining the results. Because, besides the user having accessibility, i.e. reaching the service, timely access to services can facilitate the resolution.

Access as the possibility of achieving care according to the needs has an interrelationship with the solvability and extrapolates the geographical dimension, considering that it encompasses aspects of economic, cultural and functional order of service offerings [8].

Regarding waiting to enter the appointment, Table 5 becomes necessary to elaborate strategies that will reduce the amount of time waiting for the service, once the long waiting time can cause user dissatisfaction and thus become a factor in the decrease of demand for the service. Disfavoring the establishment from user-service-professional binding and corroborating with a study made by Lima et al., (2007), in which it was found that one of the most cited complaints about the difficulties to have a good access was the amount of time patients are waiting to be attended [9].

About the proposal by professionals for home visits when the user does not go to the service, it was observed that most users said 'never'. And, as it is known, household visits are of fundamental importance, once it is where the professionals know the state of health of each individual and guarantee the principle of access, with a focus on solving the health problem, since the necessary orientations to the user and his/her family are given and, thus, the realization of continual health care.

To have access to health services, it is necessary that the services are available in quantity and quality, with qualified professionals, appropriate equipment, a location that is accessible to the community and which embraces the needs of the local population. Therefore, it is important that these factors exist so that the population may enjoy them, and that the same guarantee the quality of the provided service, as well as clientele satisfaction [5]. 
To develop a rational policy, acting in an efficient, effective, enjoyable and accessible way it is necessary to understand the health behaviors of the population attending the health system. In addition, health professionals need to be sensitized to the needs of users in order to also improve the quality of service and reorient the health system by providing compassionate care that meets the population's real needs [10].

In this sense, one knows that good access to health services favors the demand for care and the user-professional-service relationship, so that it enables the monitoring of the adult population in the PHS, and that the access to services comprises from the entrance of the individual in the unit, to the resolution of the presented need. Therefore there is still a need to coordinate actions that may involve that part of the population and promote a continuum of care, with the aim of ensuring a long and healthy life.

\section{Conclusions}

Through this study one may notice that many factors influence the access to services, such as the distance between the user's home and the Healthcare Unit, the amount of time one has to wait to be attended, the information one receives and the commitment of health professionals regarding home visits. Through this study it was confirmed that there still are gaps in the care provided to the adult population, which may impair the user's search for the service, because it is known that the support and guidance from healthcare professionals, beyond strengthening its relationship with the user, complements the search for the services and actions that may involve him.

In this context, it is expected that this study provides insights to the development of a strategic plan and sensitizes health managers and professionals in basic health care services, so that a greater interaction of the adult population with the PHC services happens, capable of providing a long life with quality by preventing the manifestation of chronic diseases and ensuring actions of basic care. There were limitations of the study, such as the exclusion of all social actors and different perspectives to assess the care model in question, and because it is local study, however, the municipality has the same reality with other cities.

Brazil's efforts in the process of strengthening the PHC deserves highlighting, because it is a level of attention focused on the family and community, capable of bringing changes in welfare model. Thus it converges with the implementation of measures that will adopt a service of quality and full time for the adult population, aiming at a full and dignified assistance to users, prepared for the promotion of health and disease prevention.

\section{References}

[1] Corrêa, A.C.P., Ferreira, F., Cruz, G.S.P. and Pedrosa, I.C.F. (2011) Access to Health Services: Glancing Users of a Family Health Unit. Revista Gaúcha de Enfermagem, Porto Alegre (RS), set., 32, 451-457. http://dx.doi.org/10.1590/S1983-14472011000300003

[2] Starfield, B. (2002) Primary Care: Balancing Health Needs, Services and Technology. UNESCO, Ministry of Health, Brasília, 726 p.

[3] Sousa, M.F. (2007) Family Health Program in Brazil-Analysis of Inequality in Access to 
Primary Care. Department of Information Science and Documentation Brasilia University, $250 \mathrm{p}$.

[4] Carvacho, I.E., et al. (2008) Factors Associated with Earlier Access to Pregnancy to Health Services for Pregnant Adolescents. Revista de Saúde Pública, 42, 886-894.

[5] Marsiglia, R.M.G. (2012) Universal Access to the Unified Health System in Brazil: Challenges for Primary Health Care. Cadernos de Terapia Ocupacional da UFSCar, São Carlos, 20, 317-325.

[6] Trad, L.A.B. and Esperidião, M. (2005) User Satisfaction Rating. Ciência \& Saúde Coletiva, 10, 303-312.

[7] Ramos, D.D. and Lima, M.A.D.S. (2003) Access and Receptivity to Users in a Health Unit in Porto Alegre, Rio grande do sul, Brazil. Cadernos de Saúde Pública, Rio de Janeiro, 19, 27-34. http://dx.doi.org/10.1590/S0102-311X2003000100004

[8] Souza, E.C.F., Vilar, R.L.A., Rocha, N.S.P.D., Uchoa, A.C. and Rocha, P.M. (2008) Access and Quality Care in Primary Care: An Analysis of the Perception of Users and Health Professionals. Cadernos de Saúde Pública, Rio de Janeiro, 24, S100-S110.

[9] Lima, M.A.D.S., et al. (2007) Access and Quality Care in Health Facilities in View of Users. Acta Paulista de Enfermagem, 20, 12-17. http://dx.doi.org/10.1590/S0103-21002007000100003

[10] Shaikh, B.T. and Hatcher, J. (2005) Health Seeking Behaviour and Health Service Utilization in Pakistan: Challenging the Policy Makers. Journal of Public Health, 27, 49-54.

http://dx.doi.org/10.1093/pubmed/fdh207

\section{Submit or recommend next manuscript to SCIRP and we will provide best service} for you:

Accepting pre-submission inquiries through Email, Facebook, LinkedIn, Twitter, etc. A wide selection of journals (inclusive of 9 subjects, more than 200 journals)

Providing 24-hour high-quality service

User-friendly online submission system

Fair and swift peer-review system

Efficient typesetting and proofreading procedure

Display of the result of downloads and visits, as well as the number of cited articles

Maximum dissemination of your research work

Submit your manuscript at: http://papersubmission.scirp.org/

Or contact ojepi@scirp.org 